\title{
Long-Term Care for Elderly
}

National Cancer Institute

\section{Source}

National Cancer Institute. Long-Term Care for Elderly. NCI Thesaurus. Code C16801.

Long-term care encompasses a broad range of help with daily activities that chronically disabled individuals need for a prolonged period of time. 